\title{
INTERNET, TRANSMÍDIA E AUDIÊNCIA PARTICIPATIVA NO UNIVERSO DAS EMISSORAS DE TV ABERTA BRASILEIRAS
}

\author{
Internet, transmedia and participatory audience in the world of open brazilian \\ tv stations
}

\section{Internet, transmedia y audiencia participativa en el mundo de las estaciones abiertas de televisión brasileñas}

\begin{abstract}
Karla Caldas Ehrenberg
Doutora em Comunicação Social pela Universidade Metodista de São Paulo (UMESP) e professora dos cursos de Graduação em Jornalismo e Comunicação Social (PP e RTV) do

Centro Universitário Adventista de São Paulo (UNASP)

karla@rk28.com.br
\end{abstract}

Rogério Furlan de Souza

Mestre em Comunicação Social pela Universidade Metodista de São Paulo (UMESP) e professor dos cursos de Rádio, TV e Internet da Faculdade Cásper Líbero e de Comunicação Social (PP e RTV) do Centro Universitário Adventista de São Paulo (UNASP) rogerio@rk28.com.br

\section{Resumo}

A consolidação da internet e de novas plataformas midiáticas possibilitou o surgimento de canais diferenciados para a produção e o consumo de produtos de entretenimento. Sob essa ótica, este artigo tem por objetivo identificar como as plataformas comunicacionais transmidiáticas influenciam o comportamento da audiência, bem como as produções dos canais de tv abertos brasileiros. Para isso, foram realizadas análises qualitativas sobre a influência do internauta no conteúdo dos reality shows Master Chef e SuperStar, transmitidos pelas emissoras Globo e Bandeirantes, e sobre as estratégias da TV Globo na criação, produção e exibição da série Supermax. Os estudos revelaram que as emissoras buscam expandir seus conteúdos para diferentes plataformas e levam em consideração a atividade da audiência conectada, porém, a participação do telespectador ainda não é capaz de interferir em todos os processos de produção.

Palavras chave: Internet. Transmídia. Audiência.

\section{Abstract}

The consolidation of the internet and new mediatic platforms enabled the emerging of distinctive channels for the consumptions of entertainment products. Under this point of view, this paper's purpose is to identify how the transmediatic communication platforms influence on the behavior of the audience and the open Brazilian TV channels. For that, qualitative analyses were performed on the internet user's influence on the content of Reality Shows Master Chef and SuperStar, transmitted by the open Brazilian TV stations Globo and 
Bandeirantes, and on TV Globo's strategies on creating, producing and screening of the TV series Supermax. Studies show that the TV stations seek to expand their contents to different platforms and take into consideration the connected audience's activity, however, the participation of the viewer is not yet capable of interfering in all the production processes. Key words: Internet. Transmedia. Audience

\section{Resumen}

La consolidación de la Internet y de nuevas plataformas midiáticas han posibilitado el surgimiento de canales diferenciados para la producción y consumo de los productos del entretenimiento. Bajo esa óptica, este artículo tiene por objetivo identificar cómo las plataformas comunicacionales transmidiáticas influencian el comportamiento de la audiencia, así como las producciones de los canales de televisión abiertos brasileños. Para eso, fueron realizados análisis cualitativos sobre la influencia del internauta en el contenido de los reality shows Master Chef y SuperStar, transmitidos por las emisoras Globo y Bandeirantes, y sobre las estrategias de TV Globo en la creación, producción y exhibición de la serie Supermax. Los estudios revelaron que las emisoras buscan ampliar sus contenidos a diferentes plataformas y tienen en cuenta la actividad de la audiencia conectada, sin embargo, a las que la participación del telespectador todavía no es capaz de interferir en todos los procesos de producción.

Palabras clave: Internet. Transmedia. Audiencia.

\section{INDIVÍDUOS, CONEXÕES E NOVAS CONFIGURAÇÕES SOCIAIS}

A presença da internet, a interligação de conteúdos em rede e a utilização qualitativa de dados e algoritmos impulsionaram mudanças estruturais em diferentes campos sociais. Paradigmas já consolidados encontram-se em um momento de questionamentos, adaptações e mutações. Nesse sentido, é possível afirmar que a comunicação realizada no ambiente conectado possui características próprias que precisam ser analisadas para que seja possível a compreensão dos processos que ali habitam.

A pluralidade de atores nos processos de produção, distribuição e consumo de conteúdos é fator bastante importante que deve ser avaliado dentro desse contexto. A colaboração, essencial elemento construtor da rede, possibilitada pelos avanços nos suportes (como computadores, celulares etc) e baseada em softwares e aplicativos, é a responsável por mudanças comportamentais bastante intensas nos indivíduos e, consequentemente, nas relações sociais.

Qualquer pessoa com acesso à internet e um mínimo de tecnologia de transmissão de dados pode produzir e distribuir textos, vídeos, fotos e animações com temas variados, ampliando os bancos informacionais, antes restritos aos grandes conglomerados de mídia. 
Esse fluxo de conteúdos oriundos dos mais diferentes atores é a mola propulsora para fazer da internet o grande espaço onde tudo está e tudo se encontra. De acordo com DiFelice,

Surge, assim, um social inédito, conectado e invisível, que se cria e se desconstrói e reconstrói continuamente alterado pelos fluxos informativos e no qual as transformações dos seus contextos acontecem através de um conjunto de networks do quais a Internet constitui o sistema operativo. $\mathrm{O}$ resultado de tal condição é que o social deixa de ser somente que está na nossa frente, observável e reconhecível, para, uma vez descolado também nas redes, se tornar um conjunto infinito de informações a ser reconstruído e reinterpretado por nós.” (DI FELICE, 2012, p. 17)

Essa produção colaborativa de conteúdos ganha maior amplitude com as possibilidades de compartilhamento proporcionadas pela estrutura da rede. No ambiente digital, um conteúdo não precisa ser produzido apenas a partir do zero, como algo único e inédito, ele pode ser elaborado por meio da interligação de vários outros conteúdos provenientes de fontes diversas. Nas palavras de Ferrari (2010, p.86), os conteúdos, pessoais ou coletivos, "serão remixados, numa eterna bricolagem de narrativas, sejam elas textuais, imagéticas, audíveis ou sensoriais".

Shirky (2011, online) analisa que com a internet "a produção social pode agora ser muito mais efetiva do que já foi, tanto em termos absolutos quanto em relação à produção formalmente gerenciada, porque o alcance e a vida útil do esforço compartilhado saíram do âmbito doméstico para a escala global", apesar de destacar que considera o compartilhamento algo inerente às dinâmicas sociais de uma forma geral.

A colaboração e o compartilhamento fortalecem uma característica bastante importante do meio digital conectado, sua capacidade dialógica. Os processos comunicacionais no ambiente digital pressupõem conversa, troca, e não apenas transmissão de mensagens. Mesmo que a interatividade já seja identificada em meios considerados tradicionais como a TV e o rádio, nesses ambientes ela acontece por caminhos previamente determinados, de maneira reativa e limitada. No âmbito da internet essa interação é chama de mútua e se consolida em tempo real, de forma complexa e por caminhos desconhecidos até que ela se concretize (PRIMO, 2008). O dinamismo presente no processo dialógico conectado impulsiona trocas de conteúdo de maneira frenética, gerando um movimento veloz e contínuo de produção, distribuição e consumo de todo e qualquer tipo de conteúdo.

A essas características soma-se a autonomia que os usuários da rede possuem no momento do consumo das produções ali disponibilizadas. O formato fragmentado da rede e 
sua não linearidade na disponibilização dos conteúdos permite uma navegação reticular individualizada, em que cada indivíduo determina sua "programação", sua sequência de consumo, o que contribui para a complexidade do ambiente. Assim, os indivíduos tornam-se mais ativos, desejam estabelecer contato com diferentes pessoas, empresas ou instituições, esperam que suas solicitações sejam respondidas (rapidamente) e anseiam por visibilidade (e por isso avançam os aspectos da exposição pública para patamares surpreendentes). Para Di Felice (2012) cada elemento da rede influencia o seu sistema, e a rede como um todo influencia cada elemento, sendo realizada uma alteração de posicionamentos, funções e atividades constantes.

O caráter cognitivo da rede, a arbitrariedade de sua forma, a não linearidade, a sua propensão à saída do eixo, a sua estrutura reticular e interativa e a sua não externalidade a tornam uma arquitetura ao mesmo tempo interna e externa a nós, isto é, um ecossistema do qual fazemos parte como participantes e não apenas como observadores externos e independentes. (DI FELICE, 2012, p.15)

Esse ambiente altamente colaborativo, característico da internet, ganha força com o surgimento das mídias e redes sociais. A produção de conteúdos por parte dos indivíduos impulsionou a consolidação do conceito de social mídia, que segundo Cipriani são ambientes que "promovem vida em comunidade e cooperação, possibilidade de alterar ou misturar criações de terceiros, melhor experiência on-line [...], abrindo espaço para assuntos muito específicos e colocando o usuário em primeiro lugar e no centro das atenções" (CIPRIANI, 2011, p.5). Esse foco na produção de conteúdos realizada por múltiplos atores e a capacidade dos fluxos informacionais de transitar por diferentes mídias, devido às conexões em redes, corroboram para a consolidação de um novo cenário midiático em que conceitos sobre convergência e transmídia passam a se fazer presentes e urgentes.

\section{CONTEÚDO TRANSMIDIÁTICO E O ENTRETENIMENTO NA TV}

O desenvolvimento de novas tecnologias digitais, responsáveis pelo aprimoramento da produção e também da distribuição de conteúdos, mudaram a realidade de algumas mídias conhecidas como tradicionais, que estavam acostumadas com uma estrutura de comunicação já padronizada. 
Para corresponder aos aspectos decorrentes dessa transformação midiática, alguns paradigmas inovadores surgiram e originaram práticas que tornaram-se essenciais na relação entre os veículos e seus públicos. De acordo com Jenkins (2009), a convergência dos meios de comunicação, a implementação de uma cultura mais participativa entre todos os envolvidos no processo e o conceito de inteligência coletiva são alguns desses elementos que modificaram efetivamente a forma de se comunicar. O autor analisa esse novo cenário social como sendo baseado em uma cultura de convergência, considerando que este é formado pelo

[..] fluxo de conteúdos através de múltiplos suportes midiáticos, à cooperação entre múltiplus mercados midiáticos e ao comportamento migratório dos públicos dos meios de comunicação, que vão a quase qualquer parte em busca das experiências de entretenimento que desejam. (JENKINS, 2009, p.27)

Nesse contexto convergente, onde os conteúdos não ficam restritos a um formato e um único canal de distribuição, os fluxos informacionais passam a ser mais complexos, permitindo (e impulsionando) que os produtos comunicacionais, sejam eles ficcionais ou não, transitem em diferentes plataformas, como televisão, rádio, internet, entre outras.

Em decorrência da possibilidade de consumo desses produtos por meio de multiplataformas, novas estruturas narrativas foram pensadas para produzir conteúdos cada vez mais interligados e com diversas finalidades. Jenkins (2009) classificou este método de criação como narrativa transmídia, e considerou-o como uma resposta ao processo de convergência das mídias. $O$ desenvolvimento de conteúdo transmidiático objetiva criar um universo em que o espectador possa transitar pelos mais variados meios e consumir fragmentos narrativos em diferentes canais. Busca-se, dessa forma, oferecer uma experiência de entretenimento mais completa e potencializar a compreensão dos indivíduos em relação ao produto consumido (JENKINS, 2009). Porto-Renó et al (2011) também comentam sobre as potencialidades dessa nova estrutura narrativa e salientam a necessidade de uma elaboração estratégica para que ela atinja os objetivos esperados.

A narrativa transmídia atravessa diferentes mídias e com ela é possível criar um universo ficcional ao redor da obra. Esta migração não é apenas de conteúdo, mas também algo que requer um planejamento transmidiático atento a cinco elementos fundamentais (história, audiência, plataformas, modelo de negócio, execução), que também prima por utilizar-se das potencialidades e recursos específicos de cada meio para ampliar a experiência do usuário com o conteúdo ficcional exposto. (PORTO-RENÓ et al, 2011, p. 206) 
Diversos aspectos influenciaram os processos transmidiáticos e colaborativos, que trouxeram variadas opções de conteúdos e modificaram a economia da indústria cultural. Os vários canais pelos quais esses produtos passaram a ser desenvolvidos, distribuídos e consumidos serviram como incentivo para que os públicos buscassem novos tipos de entretenimento, novas formas de comunicação online, por meio das redes sociais virtuais, e maior participação no relacionamento com as mídias (JOHNSON, 2012).

Na comparação com a internet, com os games, ou outras mídias de entretenimento, a TV pode ser considerada a mais passiva em relação ao desenvolvimento de estruturas narrativas interativas. Contudo, essa mídia tradicional tem buscado explorar as potencialidades dos conteúdos transmidiáticos, bem como incentivado a participação das audiências em suas produções, aproveitando os métodos utilizados até então nos seus produtos e adaptando-os de acordo com as novas possibilidades. Cannito (2009, p.44) ressalta que "a TV não deixou pra trás seus formatos de sucesso: eles coexistem com roupagens diferentes e misturados aos novos gêneros, e por sua vez, os gêneros e formatos antigos aproveitam recursos técnicos dos novos a fim de se renovar [...]".

Dentre os produtos televisivos que se enquadram na categoria entretenimento, os gêneros de maior destaque nas emissoras brasileiras atualmente são as teledramaturgias, representadas pelas novelas e séries, e os programas que seguem a linha reality show. É prioritariamente por meio dessas produções que as emissoras incentivam o público a interagir com o conteúdo exibido, buscando uma aproximação com os principais propósitos das obras transmidiáticas, que foram criadas para serem consumidas em múltiplas telas conectadas. Tem-se aqui a efetiva aplicação do conceito de "segunda tela", em que os consumidores não ficam restritos a primeira tela (TV), mas se deslocam para um consumo (e produção) concomitante de conteúdos em telas secundárias, como celulares, notebooks e tablets.

Com base nos diferenciais oferecidos por esses gêneros, a relação dos internautas com as produções pode ocorrer de diferentes formas. A mais básica é por meio de comentários nas redes sociais virtuais a respeito dos enredos das histórias contadas nas obras ficcionais ou sobre a atuação dos atores ou participantes dos programas. Outra forma de interação acontece quando conteúdos exclusivos são disponibilizados em mídias fora do universo televisivo, como é o caso das expansões transmidiáticas muitas vezes adotadas pelas narrativas seriadas voltadas para uma audiência de perfil mais jovem, acostumada com esse tipo de estrutura. Em uma formatação mais complexa, a interação pode acontecer de maneira a influenciar na dinâmica do conteúdo principal, como é o caso de reality shows em que seus resultados são 
baseados em votações via redes sociais online ou aplicativos desenvolvidos exclusivamente para os programas.

Esse panorama deu origem ao conceito de TV Social, no qual a programação exibida pelas emissoras reflete diretamente no conteúdo compartilhado pelos internautas nas redes sociais online (KANTAR IBOPE MEDIA, 2016). O alcance da internet e a potencialidade das conexões em rede fazem com que o espectador também possa participar da construção do conteúdo televisivo. De acordo com o Kantar Ibope Media (2016, online) "[...] uma das características dessa gigante sala de TV que agrega pessoas de todo o Brasil é que cada exibição de cada programa tem suas peculiaridades, que podem estimular a atividade dos telespectadores $[\ldots] "$.

Muitas dessas reconfigurações na produção e no compartilhamento de conteúdos televisivos, que neste cenário inovador passam a ser considerados transmidiáticos, só aconteceram em decorrência das transformações tecnológicas e comportamentais do público. Com base no contexto acima mencionado, esta pesquisa analisou três programas de duas emissoras de TV aberta no Brasil que, de alguma maneira, foram produzidos de acordo com as potencialidades oferecidas pelo universo transmidiático e atendendo às necessidades de consumo desse novo espectador conectado.

\section{INFLUÊNCIAS E RECONFIGURAÇÕES NAS PRODUÇÕES DA TV ABERTA NO BRASIL}

A investigação empírica deste artigo buscou identificar como o comportamento das audiências e as produções dos canais de TV aberta brasileiros são impactados pelas plataformas de comunicação transmidiática. Nesse sentido, foram realizadas análises qualitativas, de caráter exploratório, sobre a influência do internauta no conteúdo dos reality shows MasterChef Brasil, transmitido pela rede Bandeirantes e SuperStar, transmitido pela rede Globo. Para ampliar a análise também foram estudadas as estratégias da TV Globo na criação, desenvolvimento e exibição da série televisiva Supermax, que contou com expansões transmidiáticas, o que possibilitou à produção ser considerada como uma experiência inovadora da emissora.

Em relação aos programas do gênero reality show analisados, MasterChef Brasil é um programa no qual cozinheiros disputam entre si para saber quem será o novo talento da culinária brasileira. A produção, baseada em uma franquia televisiva de competição culinária 
criada no Reino Unido em 1990, sofreu pequenas adaptações para estar de acordo com o mercado televisivo ao redor do mundo e para atender melhor ao perfil dos públicos específicos.

A versão brasileira do MasterChef teve cinco temporadas já exibidas até 2018 e ficou conhecida como um dos talent shows de maior repercussão nas redes sociais no país. Sobre a interação do público com o conteúdo, na produção da rede Bandeirantes os internautas participam por meio da exibição das mensagens enviadas por eles via Twitter ou por outras plataformas. Este é considerado um exemplo de interação que não interfere de maneira significativa no conteúdo ou no andamento do programa, mas que movimenta intensamente o tráfego de mensagens nas redes sociais.

Durante a edição de 2015, a participação do público via Twitter foi extremamente intensa e o resultado final do programa saiu primeiro na plataforma digital. Além disso, webcelebridades foram convidadas a participar da transmissão do último episódio em um espaço separado nos estúdios da emissora. Esses influenciadores digitais comentavam sobre o programa ao vivo e publicavam conteúdos online, em um modelo diferenciado de interligação entre o mundo televisivo e o das conexões em redes.

O universo das redes sociais digitais também invadiu a edição de alguns vídeos na final de 2016, em que a linguagem dos memes e gifs foi utilizada para satirizar a participação dos jurados, criando um clima de irreverência e descontração, e valorizando a produção originária dos internautas.

Quanto ao modelo de participação do público adotado pelo MasterChef Brasil, em que os comentários dos internautas simplesmente aparecem na tela, a interação pode ser considerada, ainda, bastante limitada e mantém a audiência em um lugar de espectador/observador. A diferença dos padrões "pré-internet" é que suas mensagens agora são divulgadas para mais pessoas.

Já o reality show SuperStar aborda uma disputa entre bandas que se apresentam tanto para a avaliação de jurados quanto para o público que se encontra no estúdio ou em suas casas, estes podem votar em tempo real e definir quem continua no programa. Todo o processo interativo acontece por meio de um aplicativo ${ }^{1}$, que pode ser baixado em dispositivos móveis e também no computador. Em relação aos resultados da disputa, eles são

\footnotetext{
${ }^{1}$ Disponível em: <http://gshow.globo.com/participe/noticia/2016/03/baixe-o-aplicativo-do-superstar-vote-edecida-competicao.html >. Acesso em 14 Dez 2017.
} 
mostrados em tempo real durante a participação do telespectador, além disso, o internauta pode escolher se sua foto deve aparecer no programa assim que o voto foi computado.

Outras estratégias adotadas pelo reality show musical para estimular a participação da audiência foram a criação do quadro "Sala de Interatividade" e do programa "SuperStar Web", este localizado na página da atração na internet. No site do programa também era possível encontrar um chat para publicação de mensagens e perguntas, chamado "Na Telinha", além do "Rede SuperStar", espaço destinado para a inscrição de bandas que tivessem interesse em participar da disputa.

O quadro "Sala de Interatividade" acontecia em um espaço físico construído no estúdio para que uma das apresentadoras recebesse as bandas que acabavam de se apresentar ao vivo. Ali acontecia uma conversa rápida com os integrantes e também ocorria o estímulo no uso das redes sociais, já que a banda interagia com os internautas por meio de perguntas enviadas através do aplicativo ou pelo uso de hashtags. Em relação ao produto expansivo "SuperStar Web", ele era formado por conteúdos exclusivos, como informações de bastidores e enquetes destinadas aos internautas. Nelas, o público podia interferir no andamento do programa e decidir, entre outras coisas, o tipo de figurino que seria utilizado por uma das apresentadoras na próxima exibição do programa ao vivo na TV.

As questões pontuadas demonstram que o SuperStar da rede Globo adotou métodos convergentes baseados em uma participação efetiva e direta dos usuários em relação ao programa. Por meio das votações os telespectadores definem o resultado das disputas e contribuem de maneira ativa com o conteúdo. Neste sentido, a interação se aproxima dos padrões vivenciados na internet, em que a atitude de um dos atores interfere nos rumos do processo dialógico. Entretanto, é importante salientar que essa interação não é tão livre quanto na internet e que os espectadores não podem atuar da maneira como desejarem, ficando restritos aos meios preestabelecidos pelo próprio canal de televisão.

Em relação ao fluxo dos comentários nas redes sociais provenientes das produções televisivas, números do Public ITTR, ranking baseado em métricas e que mensura o conteúdo das publicações no Twitter, mostram que, em 2015, 80 programas de TV estiveram presentes nas listas do ITTR como assuntos de maior destaque no Twitter, gerando 47 milhões de tweets e 1,9 bilhão de impressões. A pesquisa relatou também que no ranking top 20 das exibições de TV aberta com mais impressões no Twitter, os programas do gênero reality show estavam no topo do ranking e apareciam em 15 oportunidades (KANTAR IBOPE MEDIA, 2016). 
As análises dos dois programas aqui estudados possibilitam perceber a junção da linguagem televisiva com os atributos interativos oferecidos pela internet e evidenciam que a contribuição dos telespectadores no desenvolvimento dos programas de TV é um caminho possível, já que as emissoras conseguiram diminuir a distância até o seu público por meio das ferramentas digitais e das conexões em rede.

Ao direcionar a análise para as produções televisivas do gênero ficcional que buscaram utilizar narrativas transmídia em seu processo de criação, esta pesquisa adotou a série Supermax como objeto de estudo. Com direção geral de José Alvarenga Jr., Supermax foi ao ar em 2016 como uma iniciativa pioneira da TV Globo de inovar o panorama dos seriados no Brasil ao reunir, em um mesmo produto, elementos de ação, suspense, terror e drama.

Em busca de uma maior aproximação com o público jovem, a rede Globo fez o lançamento da série na Comic Con Experience 2015, o maior evento de cultura pop da América Latina. Nesta ocasião foi apresentado um vídeo promocional exclusivo, aconteceu uma conversa com os diretores da série e foi distribuída uma revista em quadrinhos com o teaser da história (HERMSDORFF, 2015, online).

Acreditando nas potencialidades da narrativa transmidiática, a emissora também criou um jogo digital, produziu conteúdos em vídeo exclusivos para internet (com os bastidores da série), realizou comércio online de produtos como camisetas e canecas e desenvolveu o spinoff $f^{2}$ chamado "Supermax - Por Dentro"3, disponível para os assinantes da Globo Play, a plataforma de vídeos sob demanda da emissora.

Para inovar na distribuição da série, a emissora utilizou um recurso bastante comum em plataformas como a Netflix: a disponibilização de todos os conteúdos de uma só vez. Os primeiros 11 capítulos foram liberados para os assinantes da plataforma de vídeos da Globo, antes mesmo da veiculação da série na TV aberta, ficando apenas o último episódio para ser transmitido simultaneamente em todas as mídias. Antes da veiculação do primeiro episódio na TV aberta, foram divulgados teasers, entrevistas com atores e diretores e ocorreu o lançamento oficial por meio de um pré-episódio ou "episódio zero".

Essas estratégias de divulgação, bem como as expansões do conteúdo da série, não são algo comum nas produções televisivas brasileiras, o que permite inferir que com Supermax a

\footnotetext{
2 Spin-off é um programa de rádio, televisão, vídeo game ou qualquer outra obra narrativa derivada de um produto ou trama já existentes. Eles podem se concentrar em apenas um aspecto da obra original (tema específico, personagem ou evento) ou modificar um pouco a história e suas características originais.

${ }^{3}$ Disponível em: 〈http://globoplay.globo.com/v/5362040/>. Acesso em 18 jan 2018.
} 
emissora buscou se aproximar dos conceitos de narrativa transmídia. Essa experimentação demonstra uma tentativa de atingir um público mais jovem e participativo e uma percepção de que é possível (e preciso) inovar na produção e distribuição de conteúdos televisivos de forma a se posicionarem de maneira mais adaptada ao novo panorama de consumo cultural de uma sociedade cada vez mais conectada.

\section{CONSIDERAÇÕES}

A presença da internet no cenário social já não pode mais ser considerada uma novidade, contudo, seu impacto ainda causa mudanças estruturais e paradigmais que demandam investigações e compreensão. No campo das produções de conteúdos midiáticos é possível perceber várias alterações nos processos de produção, distribuição e consumo, sendo as mais impactantes o surgimento de conteúdos transmidiáticos e a amplitude na participação cada vez mais ativa da audiência. Nesse contexto, a investigação deste artigo buscou compreender como os conceitos de convergência e transmídia impactam as produções televisivas brasileiras e o comportamento dos públicos no consumo desses produtos.

Ao analisar os reality shows SuperStar e MasterChef identificou-se que o público desses programas se interessa por contribuir na construção e divulgação de conteúdos. Seja de maneira direta (definindo o resultado), seja de forma indireta (comentando ou criando "memes" com situações do programa) a audiência atuou corroborando com a solidificação dos conceitos de convergência que consideram o movimento ativo dos públicos como parte integrante do processo comunicacional. De forma geral, as atrações do gênero reality show, nos formatos que contemplam disputas entre seus participantes e que são transmitidos ao vivo, podem abrir uma ligação direta com a colaboração dos internautas, pois possibilitam a interatividade em tempo real, o que demonstra claramente o impacto e a influência que os processos comunicacionais originados a partir das conexões em redes têm nas produções televisivas de entretenimento.

Já a série Supermax demonstrou-se como um exemplo evidente dos conceitos de narrativa transmídia apresentados nesse artigo sob a ótica teórica de Jenkins (2009). A fragmentação de conteúdos, independentes e interligados, criou um universo que não se limitava a uma única mídia e que permitia ao usuário uma experiência de consumo ampla e diferenciada em relação às produções de teledramaturgia tradicionais. Nesse caso, a participação do público não tinha como foco a exploração da interatividade em tempo real, 
como nos exemplos dos reality shows estudados, contudo, era esperado que o público fosse ativo ao percorrer os caminhos da narrativa em busca de uma extensa experiência com a história e com a produção.

Com o estudo apresentado foi possível perceber que a influência das plataformas comunicacionais transmidiáticas é crescente tanto no consumo, quanto na produção e distribuição de conteúdos de entretenimento nos canais abertos da TV brasileira. Essa influência tem modificado formatos e incentivado novas experiências, porém, algumas práticas ainda são restritas a ações básicas (como votação por meio de redes sociais e aplicativo) diante de toda potencialidade oferecida pela internet. A percepção de que o mercado do entretenimento televisivo pode expandir ainda mais suas práticas, no sentido de aproveitar tudo o que a transmídia oferece, permite aos autores deste artigo a abertura para que outros pesquisadores ampliem o arcabouço investigativo, aumentando, assim, a base do conhecimento científico sobre a área.

\section{REFERÊNCIAS}

CANNITO, Newton Guimarães. A TV 1.5 - A televisão na era digital. São Paulo: USP, 2009.

CIPRIANI, Fábio. Estratégia em mídias sociais: como romper o paradoxo das redes sociais e tornar a concorrência irrelevante. Rio de Janeiro: Elsevier, 2011.

DI FELICE, Massimo. Redes sociais digitais, epistemologias reticulares e a crise do antropomorfismo social. IN Revista USP. São Paulo. N.92, p 9-19. Dezembro/fevereiro 2011/2012. Disponível em: 〈http://www.revistas.usp.br/revusp/article/download/34877/37613〉. Acesso em 14 jan 2018.

FERRARI, Pollyana. A Hipermídia entrelaça a sociedade. In. FERRARI, Pollyana. Hipertexto, hipermídia: as novas ferramentas de comunicação digital. São Paulo: Contexto, 2010.

HERMSDORFF, Renato. Comic Con Experience 2015: Globo tenta reaproximação com público jovem com série Supermax. AdoroCinema. 2015. Disponível em:

<http://www.adorocinema.com/noticias/filmes/noticia-117773/>. Acesso em 16 jan 2017.

JENKINS, Henry. Cultura da convergência. São Paulo: Editora Aleph, 2009.

JOHNSON, Steven. Tudo que é ruim é bom para você. Como os games e a TV nos tornam mais inteligentes. Tradução Sergio Góes. Rio de Janeiro: Zahar, 2012.

KANTAR IBOPE MEDIA. Artigos \& Papers. Transformações na TV Social. 2016. Disponível em: <https://www.kantaribopemedia.com/transformacoes-na-tv-social/>. Acesso em $15 \mathrm{dez} 2017$.

PORTO-RENÓ, Denis et al. Narrativas transmídia: diversidade social, discursiva e comunicacional. Palabra Clave. Dez 2011, vol 14, n. 2, p.201-2015. Disponível em:

$<$ http://palabraclave.unisabana.edu.co/index.php/palabraclave/article/view/1973/2531>. Acesso em jan 2018. 
PRIMO, Alex. Interação mediada por computador: comunicação, cibercultura, cognição. Porto Alegre: Sulina, 2008, 2 ed.

SHIRKY, Clay. A cultura da participação: criatividade e generosidade no mundo conectado. Tradução Celina Portocarrero. Rio de Janeiro: Zahar, 2011.

\section{Original recebido em: 19 de março de 2019 \\ Aceito para publicação em: 14 de maio de 2019}

\section{Karla Caldas Ehrenberg}

Doutora em Comunicação Social pela Universidade Metodista de São Paulo (UMESP) e professora dos cursos de Graduação em Jornalismo e Comunicação Social (PP e RTV) do Centro Universitário

Adventista de São Paulo (UNASP). Atua como docente no MBA de Comunicação Corporativa Denominacional da mesma instituição e como professora convidada na Especialização Lato Sensu em

Gestão Estratégica de Negócios Corporativos da Universidade La Salle. Desenvolve pesquisas nas áreas de comunicação organizacional (institucional e mercadológica), comunicação digital em ambientes hipermidiáticos e esporte, tendo publicações em livros e eventos científicos nacionais e internacionais. É coordenadora do grupo de estudos Gecim, do UNASP, e pesquisadora do Gepecom da EEFE, da USP.

\section{Rogério Furlan de Souza}

Mestre em Comunicação Social pela Universidade Metodista de São Paulo (UMESP) e professor dos cursos de Rádio, TV e Internet da Faculdade Cásper Líbero e de Comunicação Social (PP e RTV) do

Centro Universitário Adventista de São Paulo (UNASP). Tem experiência nas áreas de roteiro, produção, edição, captação e direção de imagens. Atuou na TV UOL, TV Unifesp, SBT e em eventos como Jogos Para-Panamericanos México 99, Panamericanos Rio 2007, UNCTAD XI, São Paulo

Fashion Week, Fashion Rio, Casa dos Artistas II e Fórum Social Mundial. Na área acadêmica, coordenou Agências Experimentais, projetos de Conclusão de Curso e participou de Congressos e Bancas Avaliadoras. Destaque para o envolvimento na criação do projeto pedagógico do curso de Rádio e TV do UNASP | EC, bem como na concepção e coordenação dos Projetos Integrados desenvolvidos em cada semestre.

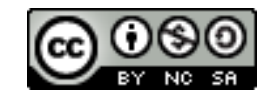




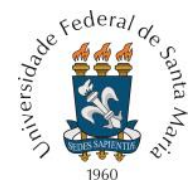

PROGRAMA DE PÓS-GRADUAÇÃO EM COMUNICAÇÃO DA UNIVERSIDADE FEDERAL DE SANTA MARIA

Esta obra está licenciada com uma Licença

Creative Commons Atribuição-NãoComercial-CompartilhaIgual 4.0 Internacional 